\title{
ON SOME IONIC ELEMENTS IN ATTIC TRAGEDY.
}

Among the happy circumstances which in the fifth century B.c. favoured the development of Hellenic art must be reckoned as an important element the peculiar distinctions and relations of the Hellenic dialects. These relations were such as it would probably be difficult to parallel. The several idioms, most of them separately cultivated up to the standard of literature, differed from each other sufficiently to make their broad characters readily perceptible, and yet resembled each other sufficiently to be mutually intelligible. Each of the great branches of the cousinhood had its own characteristic product, and the total of these was the common inheritance of the nation. The language thus resembled an organ with several sets of stops; poetry was at once provincial and classic; and the literature enjoyed by a felicitous balance the conflicting advantages of fixed and fluctuating speech. That the great artists of Athens perceived their own strength is in a general way sufficiently obvious. The distinction between the Doric chorus and the Attic dialogue is alone a proof of the fact. But it seems not unlikely that closer examination may reveal to us more subtle applications of the same method, and that, besides the keener perception which we may thus gain of the tone and feeling of particular passages, we may even be able to employ our knowledge of such laws as an instrument of criticism and interpretation. This paper is an attempt to represent under this aspect the facts respecting the use by the three tragedians of the substantives

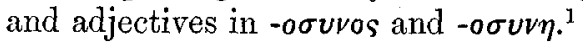

As it happens that some of the words so formed are among the most wide-spread and familiar in the Greek language, we

\footnotetext{
1 For a very full list of these forms see Iobeck, Pathologia, Diss. IV. cap. 6.
} 
perhaps hardly realise the extremely limited and special range which belongs to them as a class. As free elements of composition ready to combine with a fresh stem at the pleasure of the writer, these terminations can hardly be said to exist out of the dactylic verse of the rhapsodists and the gnomic writers who borrowed their instruments. There we find them in profusion, not only $\sigma \omega \phi \rho \circ \sigma u ́ \nu \eta, \delta \iota \kappa a \iota \sigma \sigma u v \eta$, and such trite terms,

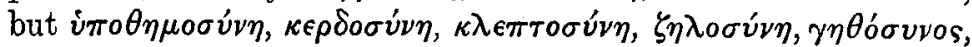
even $\theta \epsilon \mu \iota \sigma \tau o \sigma v^{\prime} \eta$, with many more. In fact the class appears in the dactylic poets as a perfectly normal formation, limited, we must suppose, only in the number of words actually current, and not in the possibility of further production. But to these conditions the Greek language generally, and in particular the idiom of Attic prose, presents a sharp contrast. Not only is the character of the class narrowly defined, but its productiveness is altogether extinct.

If we may take Thucydides-and where else are we to look? - as representing the prose Attic vocabulary of the middle and latter part of the fifth century, we find that with the exception of $\mu \nu \eta \mu c^{\prime} \sigma \nu \nu o \nu$, a monument (v. 11), the few terms of the kind which he employs are all ethical, $\sigma \omega \phi \rho o \sigma v i n$,

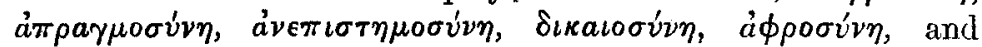
possibly one or two which I have overlooked. Now it is obvious that the mere existence of these words in the literary Attic of Thucydides' time is no proof that the suffix -ooúr was native to Athens or familiar to her streets. Ethical abstract terms of this sort are only required after a certain progress in thought and style, and as a matter of fact the first ethical writers in Greece were the gnomic poets, in whom these forms are actually found in great frequency. How and whence they came there has been already hinted.

But much more significant than the frugality of Thucydides in this species is the caution and reluctance, so to speak, with which he employs it at all : $\sigma \omega \phi \rho o \sigma u ́ v \eta$ and $\dot{a} \pi \rho a \gamma \mu \rho \sigma \dot{v} \nu \eta$ occur

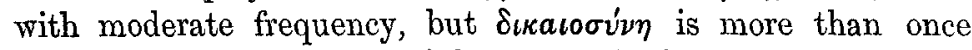
avoided by the periphrasis to sicaıov, and allowed only in iii., 64,

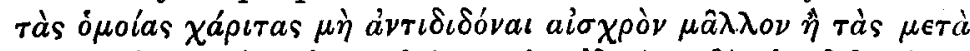

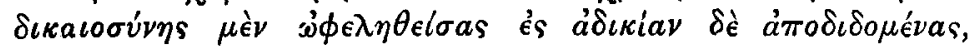
where it is plain that the substantive is necessary to the

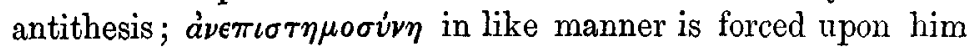


(v. 7) by the need of a euphonious counterpoise to é $\mu \pi \epsilon \iota \rho i a$, and

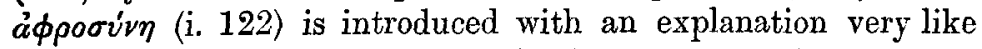
an apology to the effect that it is the proper word to express the exact negative idea which the speaker desires to denote-

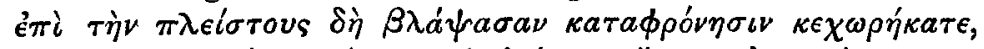

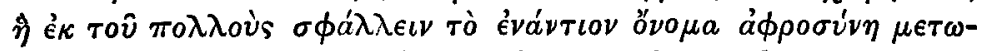
vó $\mu a \sigma \tau a \iota$. In the later Attic writers we have a larger list, but apparently of the same quality. As we are concerned only with the fifth century, it is unnecessary to descend further. Now this contrast between the language of the rhapsodists and that of Attic prose cannot be wholly explained-if it be an explanation-by classing the forms in question as poetical,

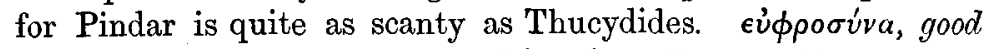
cheer, is in some vogue with him, but if we add to that a

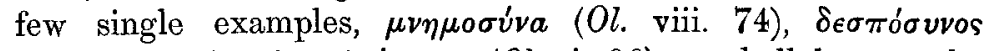

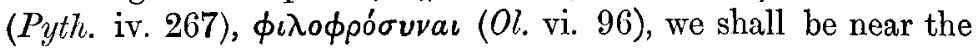
full amount. Further, the practice of the rhapsodists in respect of this termination is more liberal than that of Attic prose or of other literature generally, not only in the sense, but in the etymological form of the words for which it is permitted. With the remarkable and perhaps unique exception of $\delta$ isaı$\sigma u ́ v \eta$, every extant Attic word of this type is based upon a recognised stem in -ov-, $\sigma \omega \phi \rho o \nu-\sigma \omega \phi \rho o \sigma v ́ v \eta, a$ a $\pi \rho a \gamma \mu \nu \nu-a \dot{a} \pi \rho a \gamma-$ $\mu o \sigma u ́ v \eta$, and so forth. Even $\delta \in \sigma \pi \delta \sigma v v o s$ (if this really was in the fifth century counted an Attic word at all) is scarcely beyond the rule, for $\delta$ ć $\sigma$ moıva has the appearance of a feminine from a stem in $\nu(\delta \epsilon \sigma \pi \sigma \nu-y a)$, though as a matter of fact it appears that this $\nu$ was part of a suffix, $\delta \epsilon \sigma \pi o \tau-\nu ı$ (Curtius). But 'Epic' use ignores the rule altogether; $\kappa \in \rho \delta o \nu-(\kappa \in \hat{\epsilon} \rho \delta \omega \nu$ Lat. cerdo) no doubt existed, but $\delta o v \lambda o \sigma u ́ v \eta, \kappa \lambda \epsilon \pi \tau o \sigma u ́ v \eta$,

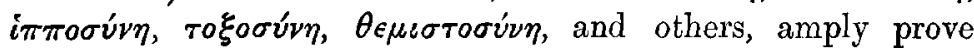

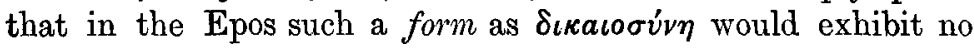
peculiarity. We may add that the cognate adjective in -ó $\sigma v v o s$ seems scarcely to have gained any footing in common Attic at all. $^{1}$ If now we ask the cause of this difference between the literary language of different schools, the explanation suggests itself that it is due to the Ionian or Asiatic origin of Epic

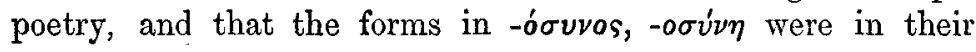

1 Compare Lobeck, l. c. 
free development a characteristic mark of the Greek spoken in Asia, which passed thence into other idioms, and ultimately into the common language of the Hellenic world, under conditions determined by the historical descent of the various species of literature and branches of knowledge. The History of the Asiatic Herodotus, though composed for general audiences at a time when intercourse must have been tending to obliterate local peculiarities in cultivated persons, nevertheless does exhibit, together with its many other Ionic peculiarities, a

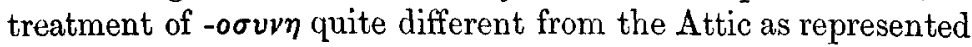

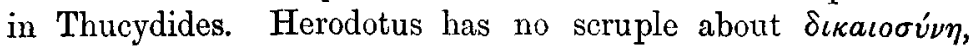

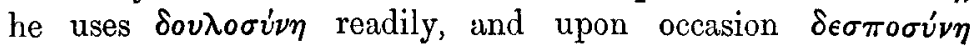
(arbitrary power), and he even slips into the provincialism, as

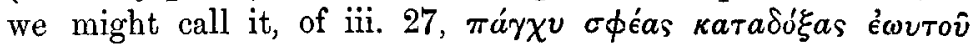

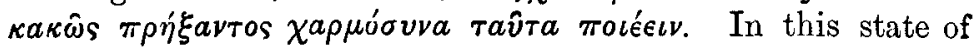
the question it becomes a matter of considerable interest to examine the examples offered by the Attic Tragedians, who employ such words, not indeed very frequently, but certainly without respect to the Attic rule as we should gather it from other evidence. If we are right in conjecturing that, during the period in which the great tragedians wrote, the termination

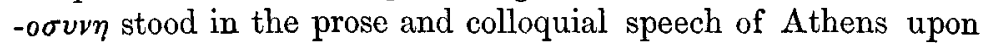
a narrow if not precarious footing, while in the large mass of popular poetry, the tale of the bard and the proverb of the moralist, the same termination was prevalent and characteristic -then it is impossible to suppose that Aeschylus and his successors can have introduced such forms into the midst of their works without regard to the association which they would carry to the ears of the audience, any more than a poet of our own day could suddenly and without reason introduce a fragment in the idiom of Burns, or make the archaisms of the Elizabethan age fit unobserved into a composition essentially modern, or use the familiar phraseology of the Bible or the Prayer-book exactly as if it had never been heard before. Such associations may of course be utilised with the most admirable effect, indeed to have power over them is the very perfection of linguistic art; but they cannot with impunity be ignored. The practice of the tragedians then will give us a crucial test for the correctness of our hypothesis, and at the same time if a large number of examples should prove to be 
consistent with the hypothesis, we shall understand them better by their mutual aid, and also obtain the means of discrimination in others of more difficulty.

But before entering upon this examination I wish to limit precisely the conclusion to which it is intended to lead. With the vexed questions relating to the history of the Ionic and old Attic dialects we have not any immediate concern. It would be nothing or very little to my present purpose if there was once a time when the speech of Athens was indistinguishable from the speech of Miletus, and if at that time words in

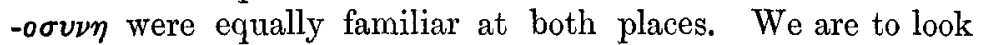
neither forward nor backward from the fifth century, the age of tragedy. In tragedy, as will appear, these words are used in such circumstances only as point to language and literature of Asiatic growth or descent. The instances are far too numerous and diverse to be attributed to accident, and the fact of peculiarity remains equally true and important, whether it be the peculiarity of archaism or of modernism. Indeed both explanations might be true at once. Some words might be survivals from an older Attic, others recent or contemporary importations from the living Ionic. However, I dismiss this extraneous discussion and come to our proper field.

We will begin upon a knot quite sufficiently tough to try the edge of our instrument-

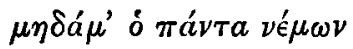

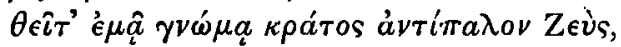

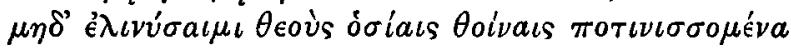

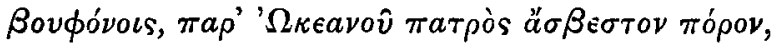

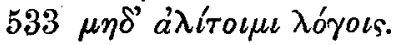

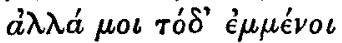

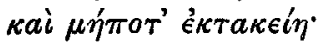

$\dot{\eta} \delta \dot{v} \tau \iota \theta a \rho \sigma a \lambda \epsilon ́ a \iota s$

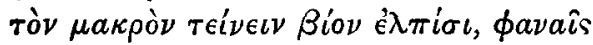

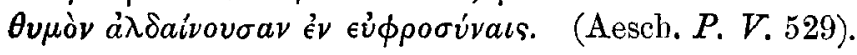

The lines of the antistrophe answering to 533-5 are these :

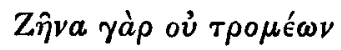

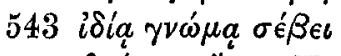

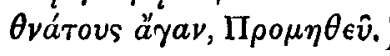


The metrical discrepancy between 534 and 543 has been

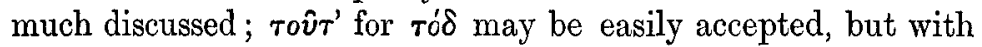
deference to the opinion of Hermann, who wrote $\mu a ́ \lambda a$, I will venture to insist that $a^{\prime} \lambda \lambda a^{\prime}$ is right and necessary, and so is

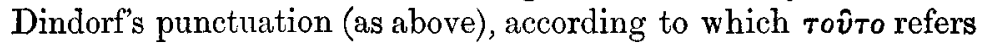
to the words $\dot{\eta} \delta \dot{v} \tau \iota, \kappa, \tau . \lambda$. The commencement of the sentence $\mu a ́ \lambda a \mu o r$ without a conjunction is highly objectionable, and the proposed use of $\mu a$ á $a$ different, as the index will show, from the use of Aeschylus. Moreover when it is prayed that this may not be erased from the wax tablet of mind-for that is the metaphor implied in éктакєi - ' this' must be some maxim or sentence which might naturally be inscribed there. We do not pray that we may remember our own prayers. Such a sentence we have in what follows, Surely it is sweet to increase the lengthening life with hope assured, satisfying the soul in festal cheera prudent reflection upon the advantages of contented comfort and the danger of risking your peace for a forbidden ideal. It is so far then encouraging for our search that these lines con-

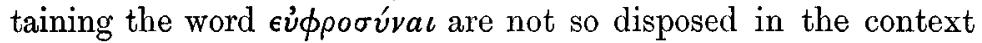
but that we may rationally suppose them quoted or adapted from some other place. It remains to see whether they offer any positive evidence that they are. Now their vocabulary is highly peculiar; $\theta a \rho \sigma a \lambda$ éos seems to be used this once only in the whole of extant tragedy, and that although it is fairly common in Attic prose, early and late; it occurs also in Homer; фavós again is found in Aristophanes, Plato, Xenophon, but not in Sophokles, not in Euripides, and in Aeschylus only this once; $a \lambda \delta a i \nu \epsilon \iota$ and (we may add without assuming the point we are

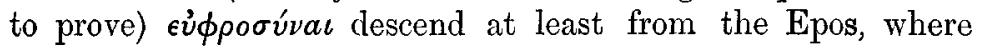

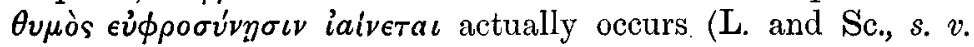

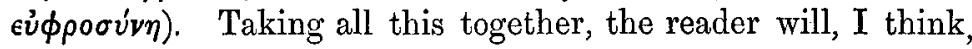
agree that such an aggregation of curiosities can hardly be fortuitous, and that Aeschylus in these lines must have had a precedent in some other poet, presumably not an Attic dramatist, and must have followed him somewhat closely. As a matter of fact he followed him word for word, for the maxim as it stands is an elegiac $\gamma \nu \omega \dot{\mu} \mu \eta$ scarcely modified,

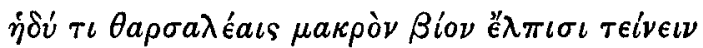

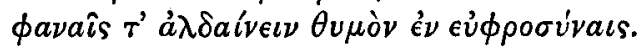


(It appears that we are hardly justified in altering the $\eta$ of $\dot{\eta} \delta \dot{v}$ - so the Med.-into $a$; if we are to alter at all, we had better

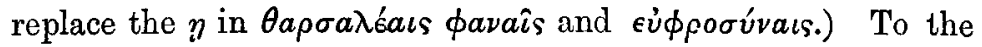

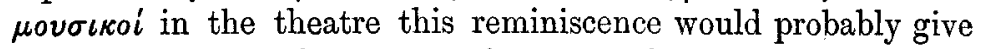
half its charm to the passage, just as a fine line in Tennyson or Milton is a thousand times finer when we can hear in it the echo of the prophets or the psalms.

I ought not perhaps to pass on without offering my word upon $i \delta i a$ in 543 , which is of course more suspicious in proportion as the reasons for retaining $a \lambda \lambda \dot{\alpha}$ in 534 have become

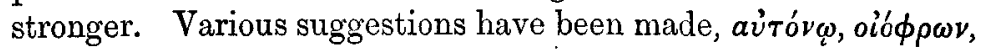
aủróßoùos $\omega^{\prime}$ (Paley, ad loc.), and probably others. The objection to them is the difficulty of accounting for the MS. text; until this is done nothing is done. The correctors assume a gloss, but aúróvous and aútóßovios would scarcely challenge explanation, while oió $\phi \rho \omega v$ would challenge it,-and defy it. We must try for something more scientific. The permutation of $\Delta$ and $\Lambda$ is proved from so many cases in the MSS. of Aeschylus, that it has a strong advantage over almost any other assumption. Will it do anything for us here? i i ia does not look hopeful, but we must remember that words have affinities of sound as well as of shape, and that such affinities have exercised a powerful influence upon copyists, as we may see from the confusion of $\kappa$ and $x$. Now if we pronounce the syllables $\iota \delta \iota a$ and $\eta \delta \in a$ in the 'itacizing' fashion of later Greek, we can hardly distinguish them. If then the uncial copy from which the Cod. Mediceus is descended had $\mathbf{H} \boldsymbol{\Lambda} \mathbf{E} \mathbf{A l}$ and this was by mistake read $H \Delta \in \mathbf{A l}$, we may safely affirm that the next scribe, particularly if he wrote from dictation, would be far more likely to wander on into i $\delta i a$ than to return to the unfamiliar and probably unintelligible $\dot{\eta} \lambda \in \hat{a}$. That Aeschylus did use this Homeric word for vain or foolish we know from

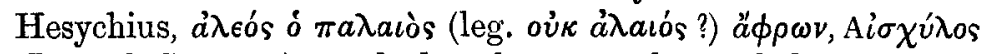
(L. and Sc. s. v.); and though we ought probably to write $\stackrel{a}{a} \lambda \in \hat{\imath}$, our MS. exhibits $\eta$ for the Doric $a$ with such frequency, not to say regularity, in all positions not final, that this difference does not affect the question. It is a confirmation of this correction that upon the analogy of it we can put right a perfectly senseless iolas in Eur. Ion 101. The Delphian ministers of Phoebus are bidden upon the day of his festival- 


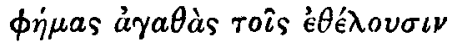 $\mu a \nu \tau \epsilon \dot{\epsilon} \epsilon \sigma \theta a$

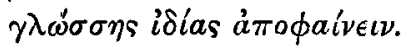

With whose tongue but their own should they utter words good or bad? For $|\triangle| A C$ write $I \Lambda \in A C$, genitive feminine from ¿ $\lambda \epsilon \omega s$, as $\pi \lambda \epsilon$ ćs from $\pi \lambda \lambda^{\prime} \omega s$, and scanned, like $i \lambda \epsilon \omega s$ itself, as a spondee. From a propitious tongue good words come naturally enough.

To proceed: the case of Persae, 584 foll. scarcely needs more than mention-

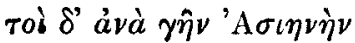

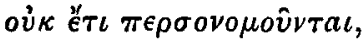

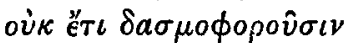

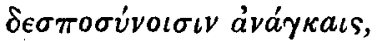

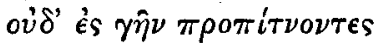

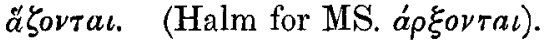

The Persian councillors are lamenting the downfall of their empire, which, as they forbode, must quickly follow the defeat of Salamis. Throughout the land of Asia the people suffer no more the Persian rule, nor pay tribute by masterful compulsion, nor worship with bowings down to the ground. The 'Oriental' tone of the chorus from which this quotation comes has been often noticed, but the quotation is pure Asiatic. To Ionic belong the pronoun $\tau o \dot{ }$ ', and the $\eta$ of the terminations $\gamma \hat{\eta} \nu$ and 'A $\sigma \iota \eta \nu \eta^{\prime}$ ' The MS. gives 'A $\sigma i a v \delta \eta v$, but it is extremely probable from the rhythm alone that Meineke was right in restoring the adjective A $\sigma$ ınvos; the MS. reading is accounted for if we suppose the Ionic form ACIHNHN to be the original. A corrector, hastily condemning this form in a Doric chorus, wrote $\mathbf{A}$ over the line; the cursive scribe reading this $\boldsymbol{\Delta}$ as so often for a $\boldsymbol{\Delta}$, put it into the line, and Doricizing as usual $\gamma \hat{\eta} \nu$ and 'A $\sigma \dot{\eta} \eta$ made what we now have. I have already suggested (Journal of Philology, ix. 147) that in the Cod. Med. the final $\eta$ when it occurs in a Doric chorus ought to be regarded as a fact requiring explanation. I shall presently show that the irregular use of these Ionic forms for special effect was known to Attic drama. $\delta a \sigma \mu o$ s and $\delta a \sigma \mu o \phi o \rho \in \hat{\imath} v$. we know that the Ionians used in reference to their Persian governors, and we may 
presume the same of $\pi \epsilon \rho \sigma o \nu o \mu \epsilon \hat{\imath} \sigma \theta a \iota ; \ddot{a} \zeta \epsilon \sigma \theta a \iota$ again, which, if $\delta a \sigma \mu о \phi o \rho o v i v \tau a \iota$ and $\pi \epsilon \rho \sigma o \nu o \mu \epsilon \hat{\imath} \sigma \theta a \iota$ are present tenses, seems

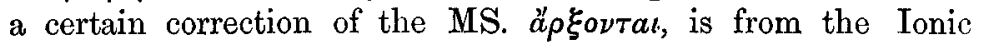
vocabulary. It is needless to observe how much this Persian lament, or rather Hellenic paean, for the deliverance of Ionian Hellas is enhanced by the significant transition to the phrases of the enslaved. Here then we may almost say that the presence of $\delta \epsilon \sigma \pi \sigma_{\sigma \nu \nu o s}$ would be strange if it were not a term borrowed from Ionic literature, and recognisable as such. But indeed if we could be sure that our 'Tyrtaeus' is genuine we might make short work, for the lines of Aeschylus are either the copy or the model of Tyrt. fragm. 4 (Bergk)-

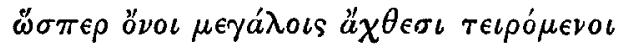

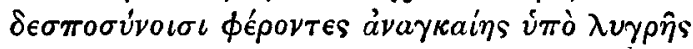

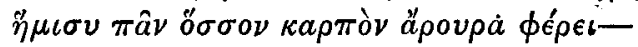

which, like most dactylic poetry, Athenian or Lacedaemonian, is palpably Ionic. Even if the resemblance of the two passages is accidental, we can see that 'Tyrtaeus' and Aeschylus drew from the same stock. Following the dramatist, I should myself read in the elegy-

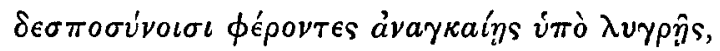

under pitiable compulsion of their lords. In the other text, $\delta \epsilon \sigma \pi$ ó $\sigma v \nu \circ$ is taken to be a substantive, a use much more than doubtful. The cognate $\delta \epsilon \sigma \pi \sigma o \dot{\nu} \eta$ appears, as has been already

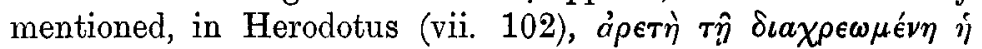

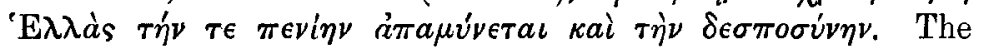
adjective itself is attributed to no prose writer except Xenophon, in this as in other matters a very uncertain 'Atticitatis auctor,' especially for the earlier half of the fifth century. Euripides

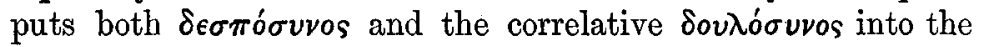
mouth of the Asiatic captive women who form the chorus of the Hecuba; they introduce themselves with their native 'Epic'-

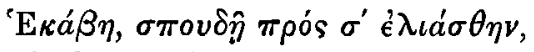

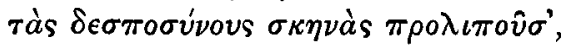
iv' $\boldsymbol{\epsilon} \kappa \lambda \eta \rho \omega \theta \theta \nu .$.

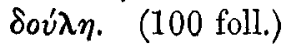


they recur to it in their self-lamentations-

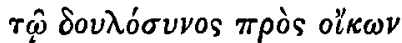

$$
\begin{aligned}
& \kappa \tau \eta \theta \epsilon i \sigma^{\prime} \dot{a} \phi i \xi o \mu a \iota \text {; (448). }
\end{aligned}
$$

and it is their last utterance before leaving the stage-

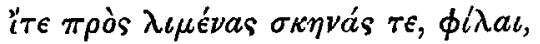

$$
\begin{aligned}
& \tau \hat{\omega} \nu \delta \in \sigma \pi 0 \sigma \dot{v} \nu \omega \nu \pi e \iota \rho a \sigma o ́ \mu \epsilon v a \iota
\end{aligned}
$$

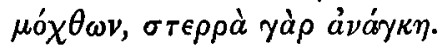

We know whence Euripides took $\lambda \iota a$ ' $\zeta_{0} \mu a \iota$, and may safely suppose that he took $\delta \epsilon \sigma \pi$ ó $\sigma$ vos also from the same vocabulary and with the same purpose, namely, to give the speech of his Asiatic women what we should call a little local colour.

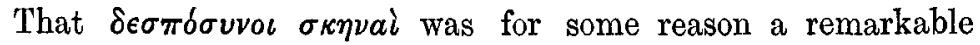
phrase to Athenian ears we may be sure from the parody upon it by the slave of Agathon, with. which Aristophanes commences his most elaborate attack upon the Euripidean school of poetry-

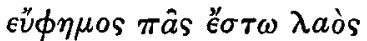

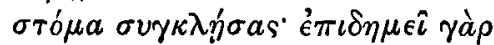

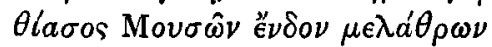

$$
\begin{aligned}
& \tau \hat{\omega} \nu \delta \in \sigma \pi \circ \sigma \dot{\nu} \nu \omega \nu \mu \epsilon \lambda \circ \pi \circ \iota \hat{\omega} \nu \text { (Thesm. 39). }
\end{aligned}
$$

Now with all this in our minds we shall perhaps be a little astonished when on turning to Choeph. 942, the triumph-song of the handmaidens over the deaths of Aegisthus and Klytaemnestra, in a passage free from suspicion of Ionism we read as follows-

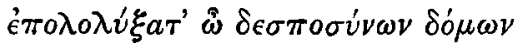

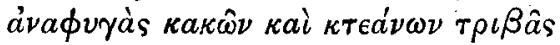

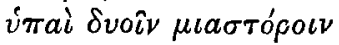

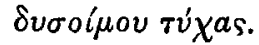

Pindar, who so often illustrates Aeschylus, no doubt has

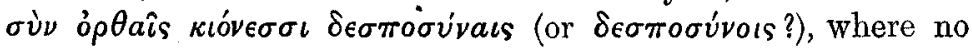
Epic or other such influence is visible. But then we have no evidence that Pindar shared the feelings which we find charac-

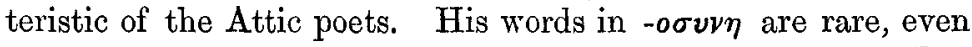
very rare, but not used with consciousness of their origin. How Aeschylus handled $\delta \epsilon \sigma \pi c ́ \sigma v v o$ s we have just seen. But what

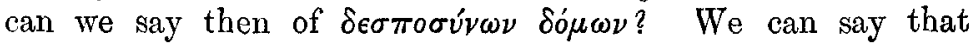


whatever may be the likelihood of such a phrase in Aeschylus, it is perfectly natural in the four lines above quoted. In spite of a certain clumsiness in their grammatical structure they are fine lines and a worthy pendant to the rest of the song. But they are only a pendant, and not an integral part of it. I have recently argued (Journal of Philology, ix. 114) from the contents and metrical structure of this ode that it contained, besides two strophes and two antistrophes, a 'burden,' which was sung after each 'verse,' though written only after the first, and which is

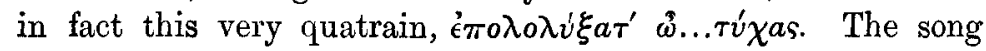
therefore is complete without it, and the notion that it was added by a later though fairly competent hand for musical or theatrical reasons is not in itself inadmissible. Let us examine the internal evidence. It is not perhaps much that we find a seemingly solitary instance of $\tau \rho \iota \beta \eta^{\prime}$ (instead of $\tau \rho i \beta o s$ ) in the sense of material waste as distinguished from the spending of time, attention, \&c. When we consider the large range of authors, including Aeschylus, who establish the contrary rule, we are justified in noticing it as a peculiarity. But as it would not be less peculiar in a writer of 400 B.c. than in one of 450 B.c., it does not go far towards our point. But a $a a \phi v \gamma \eta^{\prime}$ is doubly and trebly suspicious. Neither avaфeúr $\omega$ nor any of its kindred are cited from any other Attic author, nor from any classical author at all, except Xenophon. And this is the smallest part of the objection. The force of $a^{\prime} v a$ in the compound is somewhat obscure, but must apparently be that of the prefix re-. Now Aeschylus among several compounds with this preposition has scarcely one of this force. Accident, it may be said. Yet Sophokles has six at least,

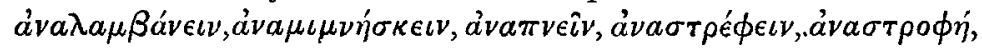
aעyai $i \eta \mu \iota$. But there is much more yet. The compounds of $\phi u y^{\prime}$ were at no time common; the introduction into Attic literature of the few which obtained vogue can be traced, and it commenced long after the date of the Choephoroe. In the fourth century we have $\kappa a \tau a \phi v \gamma \eta^{\prime}, a \pi \circ \phi v \gamma \eta^{\prime}$, and $\delta \iota a \phi v \gamma \eta^{\prime}$ (Plato); for $i \pi \nu \phi v \gamma \eta^{\prime}$ and $\pi \epsilon \rho \iota v \gamma \eta \eta^{\prime}$ we must descend to Josephus and Plutarch. Of these words катафuү' only can be traced near to the period of Aeschylus. We find it in Herodotus, but among Attic writers not until Euripides who has it several times, in prose first in Antiphon and then in Plato and Aristotle 


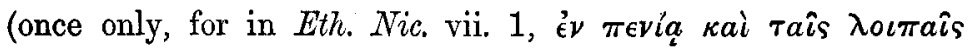

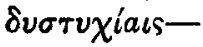

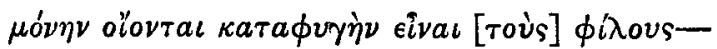

we have a citation or adaptation from the New Comedy; compare the quotation

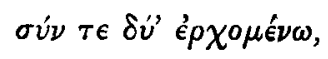

immediately below it). Of $\dot{\kappa} \phi u \gamma \eta^{\prime}, \pi \rho \circ \phi v \gamma \eta^{\prime}$, and other convenient forms there is no trace. To this negative and presumptive evidence we may add a positive proof of a very curious kind. The first seven books of Thucydides are apparently free from any such compound-this is what we should expect-and so is the eighth book, with the exception of a parenthetic clause

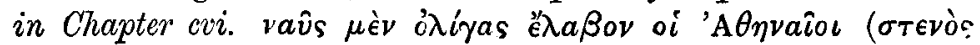

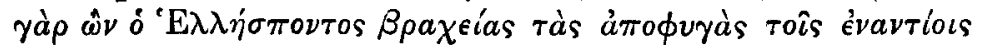

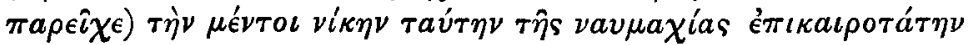
$\delta \dot{\eta} \epsilon$ É $\sigma \chi \nu$, a sentence, observe, separable from the context, and found among the last words which Thucydides wrote where we have every reason to look for the hand of his editor Xenophon.

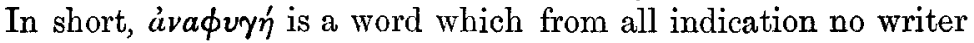
would have been likely to use before the close of the fifth century, and which no careful writer would have used at all. In a chorus of the Choephoroe it is somewhat startling.

Either then this burden of four lines was inserted as I have suggested, or Aeschylus, for some reason which I do not at present perceive, filled it with peculiarities of phraseology. The choice between these alternatives is for our present purpose indifferent.

Passing to the Prometheus, 1054 foll., we strike into an entirely new vein-

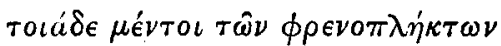

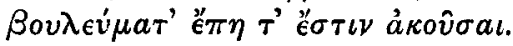

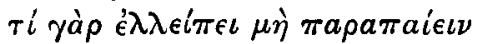

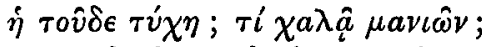

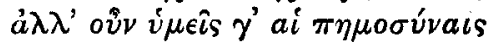

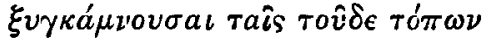

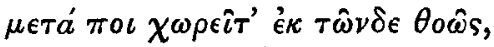

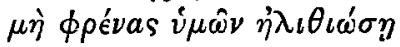

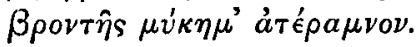


Now it was by no means through the Epos only, and by the mouth of the rhapsodists, that Hellas in Asia gave lessons to Hellas in Europe. Two important sciences, two beneficent and civilizing arts, had in Ionia, if not their earliest origin, at least their chief existing centre at the date of Attic tragedy -the arts or sciences of medicine and music. It is needless to prove or dwell upon so notorious a fact. The literary monuments of the Ionic $\phi v \sigma \iota \eta^{\prime}$ remain in part to this day; and though their music has unhappily become an almost insoluble problem, the place of its genius is stamped upon its very terms, a $\rho \mu$ ovia

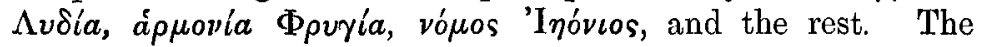
medical works which we know, and which date, the oldest of them, from the Euripidean rather than from the Aeschylean age, are in prose, and have suffered every possible depravation from the hand of time, but we may be sure that the Ionian Hippokrates had precursors, and we have seen, or shall see, reason enough to believe that these students (whether their maxims were expressed in prose, or, which is not less probable, in verse) could not designate disease by any word more natural and characteristic than the word $\pi \eta \mu$ ó $v_{v a c}$. But how are we to tell that $\pi \eta \mu \sigma^{\prime} \sigma v a_{b}$ in the Prometheres signifies disease at all? We could not tell with certainty from that one passage. In

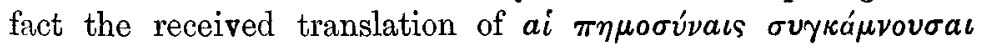

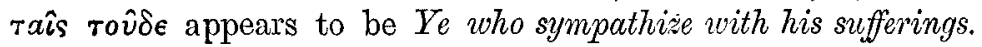
But the rendering $Y_{e}$ who are affected with his disorder, is equally admissible, and much more pointed. Or rather the point lies in this very ambiguity. 'The words of Prometheus,' says Hermes, 'are those of one clean out of his wits; ye too are touched with his complaint: beware then lest the bellowing thunder turn your giddy heads.' But to feel sure of this view we ought to have some independent evidence that $\pi \eta \mu$ ó vva $\iota$ was distinguished from other words for suffering by its association with the Ionic medical vocabulary. Fortunately we have it, in a famous fragment of Euripides, cited by two authorities, Clement of Alexandria and Themistius (No. 965, Dind. ed. 1865, No. 902, Dind. ed. 1868. Is any advantage gained by such changes of numeration?)-

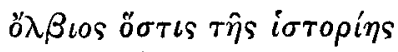

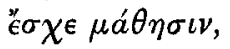




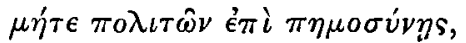

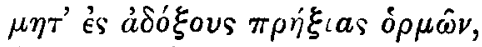

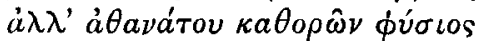
$\kappa o ́ \sigma \mu \sigma \nu \dot{a} \gamma \eta \dot{\eta} \rho \omega \nu, \tau \hat{\eta} \tau \epsilon \sigma \nu \nu \in \dot{\sigma} \sigma \tau$ [кai ö $\pi \eta$ кai ö $\pi \omega s$.

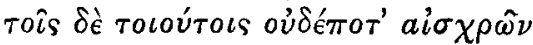

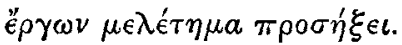

Now here at least is a passage in which the Ionic forms are

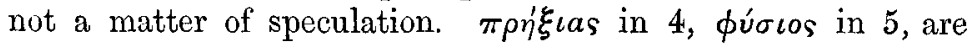
both of them MS. readings (see Dindorf, ed. 1868); in 3, Clement has $\pi \eta \eta \mu \sigma v^{\prime} \eta$, in Themistius the quotation commences

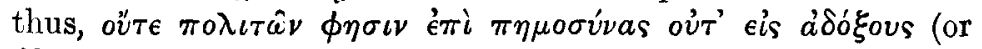

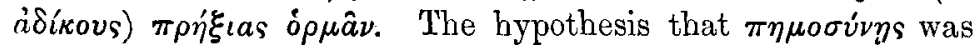
the original reading accounts, as no other will, for these varieties.

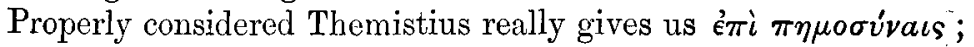
citing a part without reference to the whole, he takes those words with $\delta \rho \mu a \hat{\nu}$, and alters $\pi \eta \mu o \sigma u ́ v a \iota s$ to $\pi \eta \mu o \sigma u ́ v a s$, a slight error, but an error, as we see from the context given by

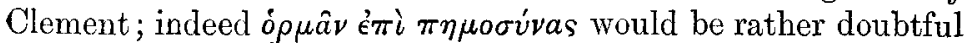
Greek: $\pi \eta \mu \sigma \sigma \dot{v} v a \iota s$ then and $\pi \eta \mu \sigma \sigma \dot{v} \nu \eta$ point unmistakably to their common origin, $\pi \eta \mu \sigma \sigma v i n s$. (We may observe that many of these forms appear chiefly in the plural, as eúppoov́val,

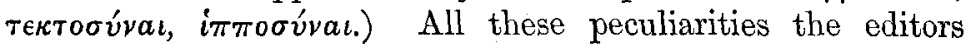
have pruned away. But to prefer the ordinary $\pi \rho a \dot{\xi} \xi \in \iota$ to the exceptional $\pi \rho \eta^{\prime} \xi$ ıas is clearly against the simplest principles of criticism if the Ionic forms can be justified. Justified? We ought to have put them back if the copyists had ejected every one. It is a matter of common knowledge (Ueberweg, Hist. Phil. $\$ 24$, s.f.) that this fragment is an apology for the Ionian Anaxagoras of Klazomenae, and of the physical studies which he followed, against the prejudices of the Athenian public. But it seems not to have been observed how deeply the lines are coloured by the phraseology of the very 'physicians' whom they defend. We brush away $\pi \rho \eta^{\prime} \xi \iota a s, \phi i \sigma \iota o s, \pi \eta \mu \circ \sigma u ́ v \eta s$, and regard with complacency our well-swept Attic. But we shall not so easily get rid of $\mu \in \lambda$ é $\eta \mu a$, Ionic as it is not in form but in substance. This exceedingly rare word is cited by lexicographers from two passages only of pure Attic literature (we shall hardly

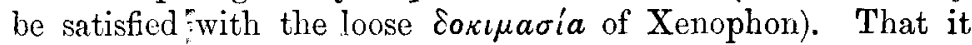

H. S.-TOI. I. 
was a property, and a characteristic property, of the Ionian physicists we may learn from Plato, who, although he naturally does not use it himself, tells us plainly, if we attend, that others

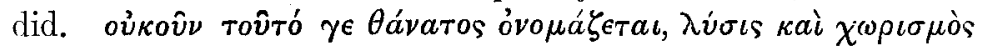

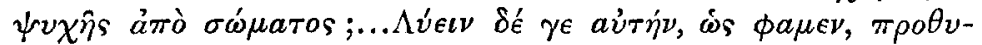

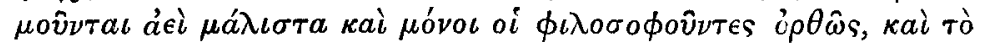

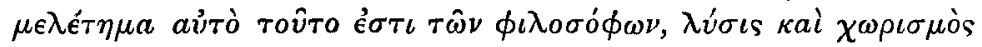
$\psi v \chi \hat{\eta} s$ àmò $\sigma \dot{\omega} \mu a \tau o s$. (Plat. Phaedo, 67. D.) Remembering Plato's habit of allusion, we might well suspect that beneath the words

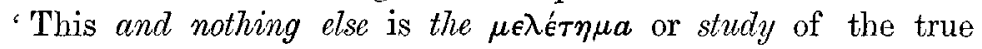
philosopher' lurks the implication that other persons claiming that title had professed another $\mu \epsilon \lambda$ ér $\eta \mu a$ ? This suspicion will of course be immensely strengthened when we notice the rarity of the word. Now who may these persons have been? Doubtless those from whom Plato took the almost unique $\chi \omega \rho \iota \sigma \mu o ́ s$, analysis, the separation of elements from a compound. This, as the dictionary will show, is the true Platonic sense of $\chi \omega \rho / \zeta \epsilon \iota \nu$, and we shall not be at a loss to conjecture where the verb first took this signification when we observe that though rare and semi-technical in Attic it is used by Herodotus in a way which shows that it was for him in familiar and colloquial use. Indeed we are not left to such indirect deduction, for Anaxagoras himself, when he wishes to distinguish his own subtle theory of the $\boldsymbol{o} \mu$ oเo $\mu$ épeıa from the crude analysis of his pre-

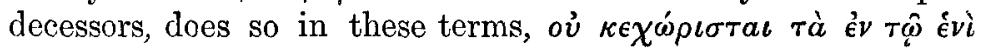

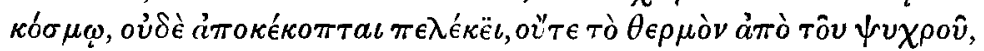

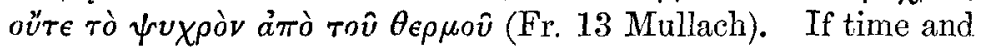
space permitted it might be shown that throughout all the remarks on the true 'separation' and the true 'study' from which the above extract is taken, Plato has in his thoughts

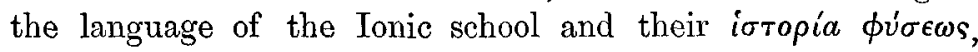
which, as every reader will remember, he openly criticises at a later point in the dialogue (Phaedo, 96 foll.). Not to be

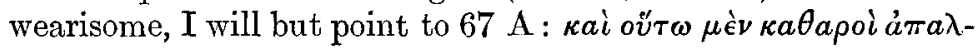

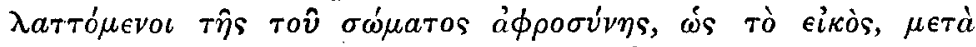

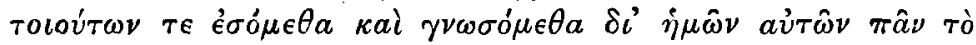

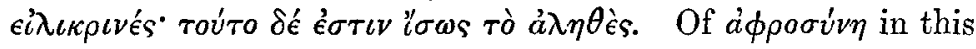
curious physical aspect we shall hear again, but notice the last words. Since Plato, it appears, meant тò ả $\lambda \eta \theta \dot{\epsilon} s$, why did he not say so at first, and why does he pretend to doubt (" $\sigma \omega \omega s$ ) the 


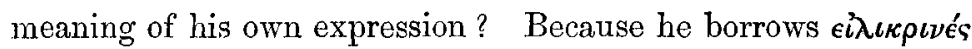
from the vocabulary which he parodies, and thinks it safer to

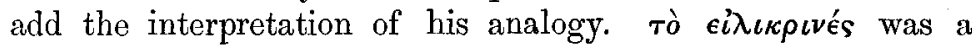
technical term for the ultimate uncompounded and inseparable unit which it was the object of $\chi \omega \rho \iota \sigma \mu$ ós to discover; see one example out of many in Aristotle, Prob. xxxi. 28, ed. Berol. 960

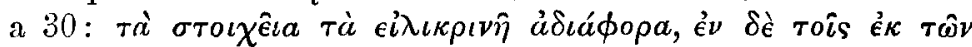

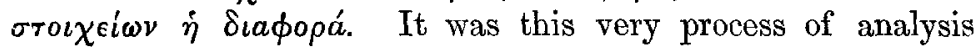

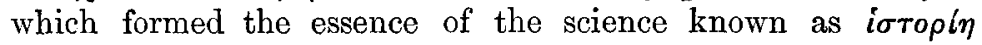

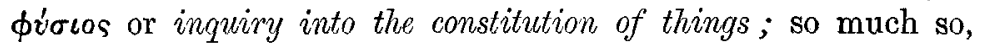
indeed, that ioropia itself, the name of the science, almost signified such a process, as we may see from a passage like Dem.

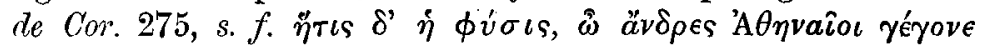

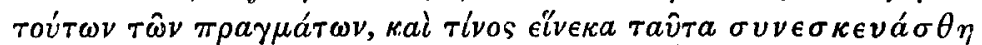

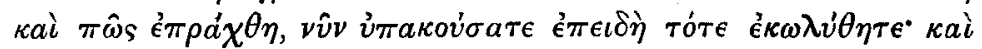

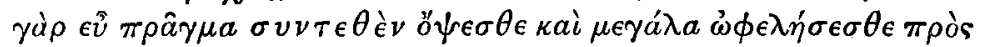

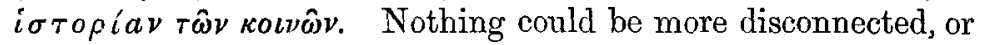
indeed more pointless, than the concluding clause, unless we remember that to an Athevian ioropía was a term of art merely, and recognise the metaphor suggested by the use of this word

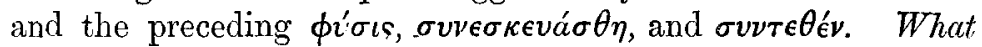
this plan was, gentlemen, in its constitution, what was the end and method of its construction, you were at the time not permitted to learn. If you will now give me your attention, you shall see an excellent piece of composition and receive an important aid towards the analysis of politics. When therefore Euripides, speaking for

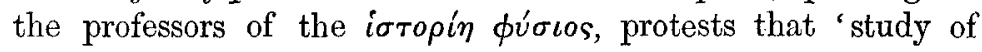
foul deeds to such as these shall ne'er belong,' and selects for study this very word $\mu \epsilon \lambda \epsilon$ r $\eta \mu a$, it is impossible to doubt that he is speaking not only the sentiments, but the language of his

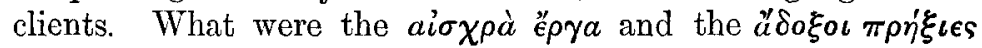
imputed by ignorance to a science much occupied with the constitution of the human body (Plat. Phaedo, 96 D); it would not be difficult to divine, even if Euripides did not specify in line 3 the insinuation that it was a science of murder. The student of nature learns, he says, not with purpose to produce 'disease' in his fellow-man nor bent upon 'practices' unseemly, but gazing upon the ageless order of immortal nature, the way, the mode, the manner

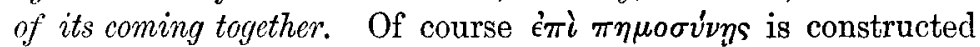

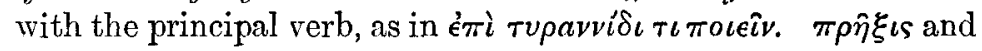


$\kappa a \theta \circ \rho \hat{\nu} \nu$ (ef. Plat. Phaed.l.c. $66 \mathrm{D}, \kappa a \theta \circ \rho \hat{\alpha} \nu \tau \dot{\alpha} \lambda \eta \theta \hat{\epsilon} \varsigma$ ) cling to the language of surgery in the form of 'practice' and 'catopsis' ('a morbid intentness of vision') to this day. It is of the Doctor of Phisik that Chaucer says, 'He was a very perfit practisour.'

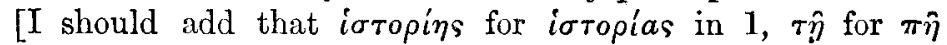
in $6, \pi \rho \circ \sigma \eta^{\prime} \xi_{\epsilon \iota}$ for $\pi \rho \circ \sigma^{\prime} \zeta \epsilon \iota$, in 9, are my own corrections. The first two hardly require comment. The copy which gives us

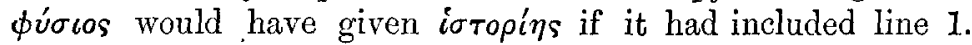
$\pi \hat{\eta}$. . . ö $\pi \eta$ cannot, it is admitted, be right, and when the semiIonic phraseology of the passage is perceived, my slight alteration, will, I think, be preferred to any other. I do not write $\kappa a \tau o \rho \hat{\omega} \nu, \tilde{o} \kappa \eta$, ö $\kappa \omega s$, as it seems safer not to carry correction beyond authority. ${ }^{\prime}$ As for $\pi \rho \circ \sigma i \zeta \in \iota$, sits $b y$, if the reader finds it intelligible he will not trouble himself with my figment; if not, $-\iota$ is precisely similar to $\eta$ in sound, and $\zeta$ (compare $a ́ \rho \xi o v \tau a \iota$

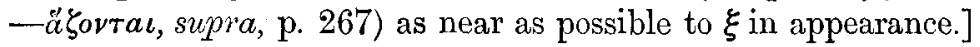

For want of the assistance afforded to criticism by observing the occurrence of a form in -oovy $\eta$ as a trace of the author's probable train of thought, a beautiful phrase of Sophokles (Fr. 658) has, if I mistake not, been utterly distorted. It is given by Dindorf from Stobaeus in this form :-

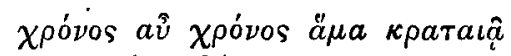

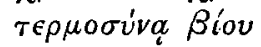

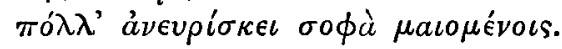

Attempts have been made to lighten the darkness of this saying

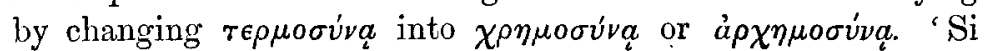

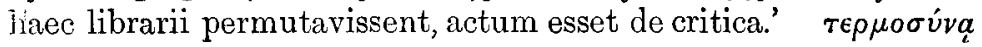
is the last word in the sentence that should be suspected, a word so rare that this is apparently the only extant example, and yet perfectly unexceptionable, for we might have safely predicted the possibility of such a form from the well-known $\tau$ '́ $\rho \mu \omega v, a$ 7oundary. Yet it is clear that the idea, ending of life, is wholly foreign to a description of Time as the Great Discoverer. But is this the true subject of these verses? Time does, we know, bring slow revelations to the race, but it is not in this aspect only, or principally, that he presents himself to the individual inquirer. Ars longa, vita brevis, has been the word of searchers

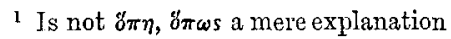
of $\tau \hat{\eta}$. $\tau \in$ (dative fem. of $\delta \sigma \tau \epsilon$ ) incor-

porated with the text through mis. understanding of the $\tau \in$ ? 
into nature from Hippokrates downwards. Many are the delays which retard their efforts, and even if they partially succeed,

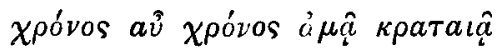

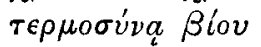

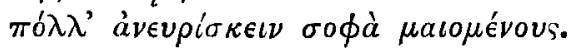

Time, cruel Time, mows then down, with peremptory bounding of their days, while yet they yearn after rich discoveries. The reader will not need to be reminded of Milton's 'blind Fury with the abhorred shears.' We shall scarcely then be rash in supposing that the poem of which this fragment is left to us bewailed the

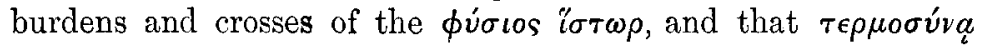

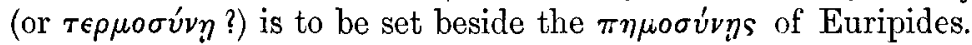
The resemblance of the language to Soph. Ant. 599-

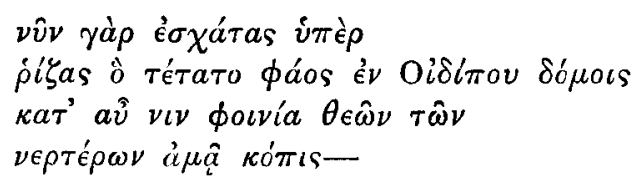

will perhaps remove doubts which have been expressed as to the authorship.

It will be convenient to take here as belonging to the topic of the Ionic medicine Eur. Hipp. 161. The chorus of Troezenian women are conjecturing the cause of Phaedra's sickness, of which it will be remembered that the chief symptom was obstinacy in fasting. It occurs to them that it may be connected with pregnancy or some other disorder peculiar to the sexual constitution of women-

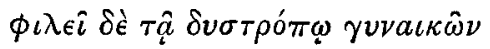

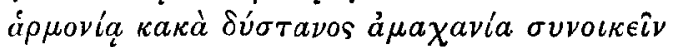

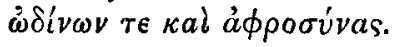

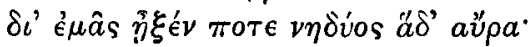

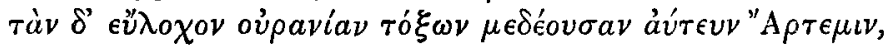

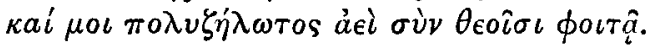

After the passages which we have just examined, the presence

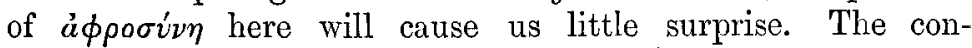
nection of loss of appetite with disorders of the womb will be found noticed in the 'Hippokratean' treatise $\pi \epsilon \rho i$

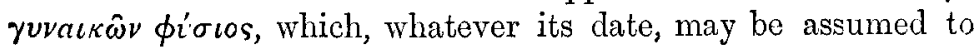




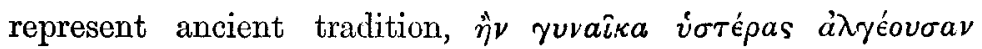

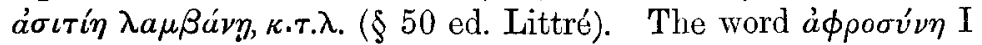
have not noticed there (though it is very likely to be found) :

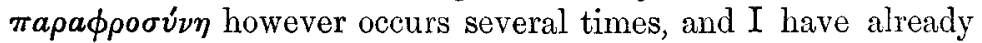

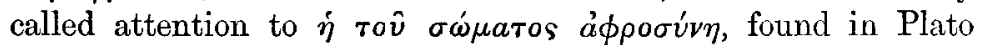
(Phaedo, l.c.) among many traces of language adapted from Ionic writers on the physics of the body. It is even more striking that the physician-poet Nikander, himself an Ionian Asiatic writing some centuries later but in thoroughly antique phraseology, employs á $\phi \rho o \sigma u ́ v \eta$ several times in this precise sense, the whims of the appetite, for example-

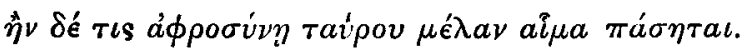

Alexipharmalia.

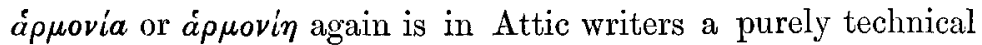
term, belonging sometimes to medicine in the sense of constitution, sometimes to music in the sense of harmony (or rather tune), and in Ar. Eq. 533, of the 'joining' of the musical instrument by which the tune is produced. In the Epos, on the other hand, and in Herodotus we find it applied without technical restrictions to any joining or joint (as between persons covenanting or the timbers of a ship, see Lex. s. v.), a sign that in Asia it was at home, and travelled thence with the spread of Asiatic teaching. It might perhaps be objected that in Aesch. P.V. 551, ápuovia stands for government (so Lex. and Comm.)

$$
\begin{aligned}
& \text { oü } \pi \omega \\
& \text { Tày } \Delta i \grave{s} \text { áprovíav }
\end{aligned}
$$

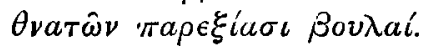

I should reply that such a rendering could not anywhere be more

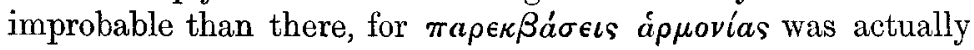
a technical term of music; Aristotle (Pol. 43, al.) quotes it as such, and illustrates by it his own phrase $\pi a \rho \epsilon \kappa \beta a ́ \sigma \epsilon \iota s \quad \tau \hat{\jmath} s$ a $\rho i \sigma \tau \eta s$ moגıteias, deflexions from the ideal constitution; and this is surely an indication that if appovia ever meant scheme of government Aristotle was unaware or oblivious of the fact; for what could be more idle than to illustrate the expression deflexion from a constitution by another expression which meant deflexion from a constitution? That Aeschylus in the maxim above cited had for some reason the language of Ionic poetry in 
his mind we see from the introduction of the Homeric not yet for never. Until the supposed apmovía government is better established than it is now, I shall be disposed to credit Aeschylus with a quainter but more picturesque metaphor-Not so soon shall the counsels of man play out of the tune of God. But now let us return to Phaedra and her friends, and let me ask the reader to notice, if he has not done so before, one of the most exquisite devices of art which poet ever employed. The Ionie language was not only the language of healing, it was also the language of worship, of those invocations or rhapsodies to the gods composed in the flowing hexameter, which must once have been a literature in themselves but are represented to us by a small and dubious collection. With admirable skill Euripides avails himself of this pre-established harmony between the tone of suffering and the tone of thanksgiving, and from 'the helplessness of travail and wood wits' passes, as by an expected modulation, into the cry of the afflicted, heard, we may be sure, not then for the first time,-

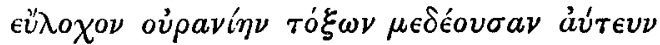

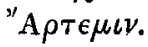

The meddling of mediaeval ignorance has blurred with its oupaviav the visible character of the hymnist's hand, but as the

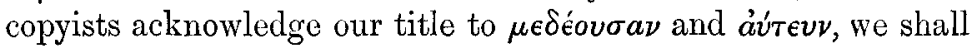
make bold to reclaim oujavin $\nu$ too.

The occurrence here of the Ionic contraction a'vitevv will naturally direct our attention to the only other passage of Euripides in which a similar contraction has been noticed as a

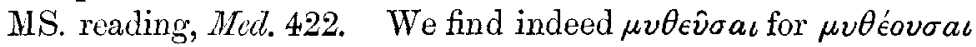
from an otherwise unknown $\mu \nu \theta \ddot{\omega} \omega$ in $I p h . A$. 790, but the place (see below) is either insanely corrupt or else full of gross solecisms, and there can hardly be a doubt that it is spurious.

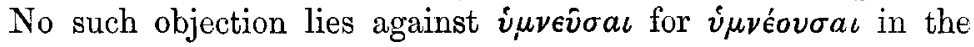
lines which follow-

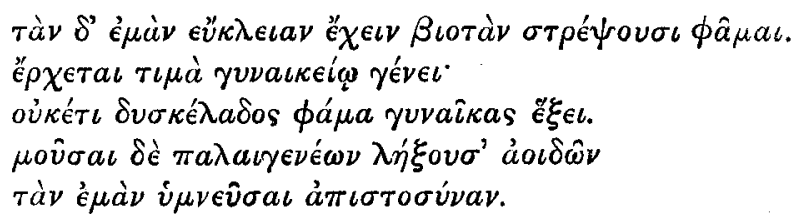


The reader will probably be able to recall the context. The chorus of women are anticipating the effect which the tale of Jason and Medea must have upon the comparative reputation of the two sexes in respect of truth and honour. After the signal instance of masculine infidelity displayed by Jason the world will repent of its outcry upon the falseness of the fair, and even the poets will abandon the topic. The last two lines, as a glance at the explanatory commentaries will show, have caused a great deal of trouble. For a $a\llcorner\delta a \nu$ the common reading, the Copenhagen MS., of some independent weight, gives a $a 0 \delta \hat{o} \nu$. Which of these two we are to read, whether aov $\delta \hat{a} \nu$ (if the overwhelming majority of MSS. be right) depends upon $\mu \circ \hat{v} \sigma a \iota$ or upon $\lambda \eta^{\prime} \xi o v \sigma \iota$, whether $\dot{v} \mu \nu \in \hat{v} \sigma a \iota$ is to be explained by a 'scilicet тo $\pi \rho i \nu$,' or to be construed with $\lambda \eta^{\prime} \xi o v \sigma \iota$, and in the latter case what becomes of aov $\hat{a} \nu$-upon these points there have been almost as many opinions as editors. All or almost all these difficulties are dispelled by the observation that the phraseology of the lines is Ionic throughout, and imitates with sarcastic purpose the diction of the rhapsodists (aoı $\delta o i)$, at whom it is pointed. That the conjunction of $\dot{v} \mu \nu \epsilon \hat{v} \sigma a \iota$ with $\dot{\alpha} \pi \iota \sigma \tau o \sigma \dot{v} v a \nu$ is a strong indication of some such purpose, I think I may by this time venture to take for granted. Now the phrases a $\rho \chi € \iota v$

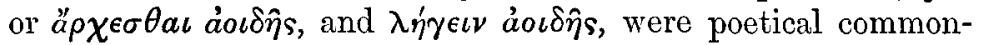
places, the Mov̂raı or some other patron of poesy being invited almost as a matter of course to 'open' and to 'close' the strain.

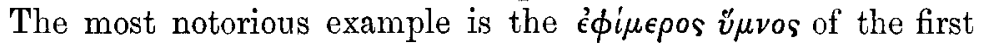
idyll of Theokritus, in which 'Thyrsis, the 'preserver' of the sacred tradition of song (Theokr. 1, 63), invokes the Muses nearly twenty times in some eighty lines, in the earlier part with

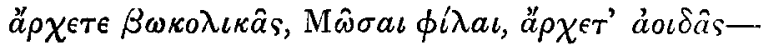

towards the end with

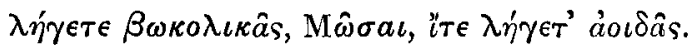

We may compare the double or treble commencement of the 'Hesiodic' Theogonia-

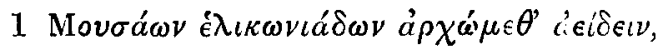
and again,

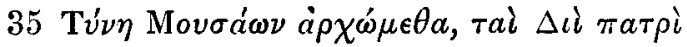

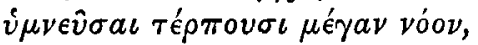


and again,

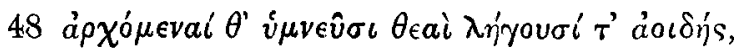

which last is the more to our purpose if it be, as some think, a spurious 'tag' inserted to stop an imaginary gap. Other illustrations might be given. It is upon the triteness and well-known significance of this phrase that the whole point of Euripides' delicate satire depends. We must remember that in Greece the art of recitation at feasts and on other occasions was a hereditary or at least traditional art, practise $]$ by professional singers (áo $\delta o i)$, who handed down from generation to generation the method, the subjects, and the substance of dactylic poetry. In what tone these persons found it profitable to speak of women we see from the invective of the Theogonia (591 foll).

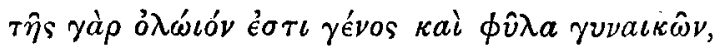

to which the editors of Euripides refer us, and which may ke taken for a specimen of the vast mass of rhapsodic poetry that has perished, and indeed was never put into a form fitted for permanent existence. It is to the poets as a class rather than to any individual poet that Euripides directs this chivalrous rebuke for their attacks upon those who could not answer them in kind :

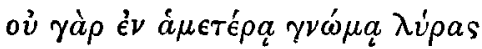 \\ $\omega ̋ \pi \alpha \sigma \epsilon \theta \epsilon ́ \sigma \pi \iota \nu$ ảo $\iota \dot{\alpha} \nu$ Фоîßos-}

a rebuke which alone is sufficient to raise questions as to the much misunderstood 'misogynism' of the tragedian. Henceforth, say the Chorus, the Muses, harping on woman's 'faithlessness,' shall 'stint' those long-descended 'lays,' for shame to find them so untrue, and thus the worn-out formula of the bards shall for once have an earnest meaning. This cruel theme has been

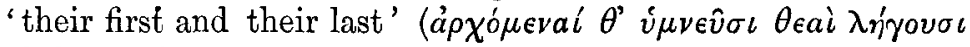
$\tau^{\prime}$ a $\left.a \imath \delta \hat{\eta} s \dot{v} \mu \nu \hat{v} \sigma a \iota\right)$; now it shall be in a new and truer sense 'their last.' From this point of view we can understand both the prevalent reading $\dot{a} o \iota \delta \hat{a} \nu$ and the single variant $\dot{a} o \iota \delta \hat{\omega} \nu$; $\dot{a} o \iota \delta \hat{\omega} \nu$ or perhaps $\dot{a} o \iota \delta \hat{e}^{\omega} \omega \nu$ is original, the genitive plural of áo: $\delta \eta^{\prime}$; the Greek editors supposing, as the modern have done, 
that $a \circ \delta \hat{\omega} \nu$ in a Doric Chorus could only be the genitive of aoıঠò, and seeing that 'songs,' not 'singers,' was the worl required, altered it to $\dot{a} o \iota \delta \hat{\alpha} \nu$, as in all probability they altered

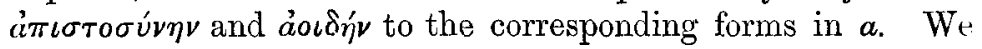
can also account for the remarkable fact that all the MSS. read in defiance of the metre $\lambda \eta^{\prime} \xi o v \sigma \iota v$. It is the work of a corrector who understood the allusion and restored without sufficient reflection the dactylic rhythm. It would be out of my purpose to consider here the similar Ionic contractions in the Prometheus Vinetus, $\epsilon i \sigma o \iota \chi \nu \epsilon \hat{v} \sigma \iota \nu(122)$, and $\pi \omega \lambda \epsilon \dot{v} \mu \in \nu a \iota$ (645). Either some reason (which $I$ do not at present see) must exist for the use of them, or they are erroneous. If I add here that in the best commentaries upon the Hippolytus and the Medea avitevv and $\hat{v} \mu \nu \epsilon \hat{v} \sigma a \iota$ are passed without any observation beyond a mere reference to the other real or supposed examples of the same form in tragedy, and that Elmsley himself actually doubted, as he well might, whether so strange a variation as $\hat{v} \mu \nu \epsilon \hat{v} \sigma a \iota$ could be genuine, I do so merely to justify my promise that attention

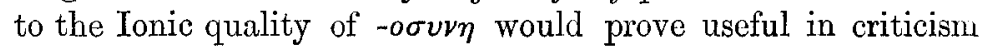
and explanation.

If any doubt could remain whether the selection of the form $\dot{\alpha} \pi \iota \sigma \tau \sigma \sigma \dot{\nu} \eta$ was or was not deliberate, we might remove it by the unimpeachable testimony of the author himself. For Euripides was sufficiently pleased with his views upon the relations between poets and women to repeat them substantially. and in part verbally in the Ion, where the chorus take the desertion of Kreusa by Xuthus for the text of a closely similar admonition.

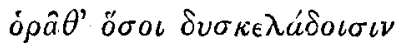

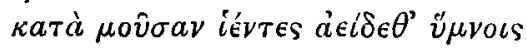

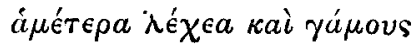

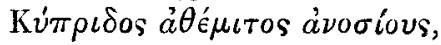

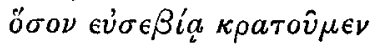

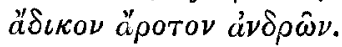

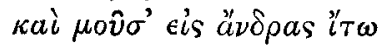

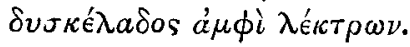

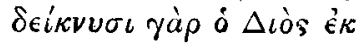 \\ $\pi a i \delta \omega \nu \dot{a} \mu \nu \eta \mu \sigma \sigma \dot{v} a \nu$.
}

$1096 \pi a \lambda i \mu \phi a \mu \circ \cos _{0} \delta \dot{a}$ 
We might be surprised, if we were not in possession of the key, to notice that here as in the Medea the sin of the traitor is denoted by a unique word of the type we are considering. Now we shall not hesitate to read the one passage by the light of the other. But it happens-and it seems likely to prove something more than a coincidence-that our clue has again led us to a place of well-known critical perplexity. It is worth while therefore to see whether the new light will help to unravel it. The chief ground of difficulty is the want of metrical correspondence. $1096-1100$ answer to the first five lines of the following extract from the strophe, the subject of which is the celebration of the Eleusinian mysteries.

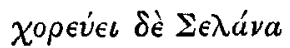

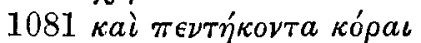

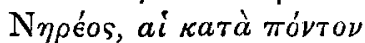

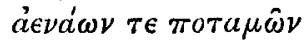

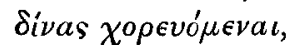

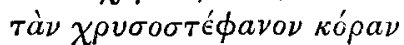

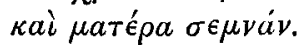

It will be seen that 1081-3 differ considerably from 1097-9, and the first question naturally is which should be altered. I will show briefly that the fault is not in the strophe. The sole word to which any exception can be taken is $\chi o \rho \epsilon v o$ ' $\mu \epsilon \nu a c$ in 1084 ; but as this participle is quite meaningless, and no correction both simple and satisfactory has been suggested, doubt has necessarily rested upon the whole clause. I venture to think that this doubt can be finally quieted. Euripides

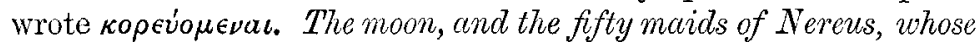
maiden life is in the sea and the curling ever-flowing streams, do dance in honour of the Maid gold-crowned and Mother

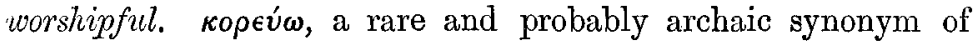

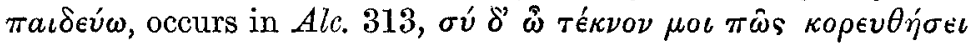

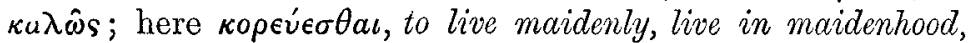
is parallel to $\pi a \iota \delta \in v \in \sigma \theta a l$, to spend the time of childhood, in

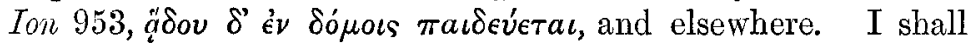
return to this word hereafter.

We can now proceed with more assurance to the correction of the antistrophe, observing however that we are at liberty to 
scan 1083 either thus reading $\dot{a} \epsilon v a \dot{\omega} \boldsymbol{\nu}$, or thus

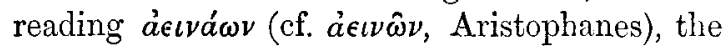
choice between these forms being, as a mere question of palaeography, indifferent. The corresponding line $\delta \epsilon i \kappa \nu v \sigma \iota$ $\gamma \dot{\alpha} \rho \dot{\delta} \Delta \iota \dot{s} s \dot{\epsilon} \kappa$ shows that $\alpha \epsilon \iota \nu a ́ \omega v$ is the true form; again, since $\gamma a \dot{\rho} \rho$ represents a long syllable, we see that $\delta$ cannot be right. The words $\delta \Delta i \grave{s} \dot{\epsilon} \kappa \pi a \iota \delta \hat{\omega} \nu$ are taken to mean he that is of the children of Zeus, that is Xuthus, who was the descendant of Zeus in the second generation; but just objection has been made to this merely as Greek, and it is oven worse when considered with reference to the context. What has this genealogical description to do with the question? It is Xuthus the man, not Xuthus the grandson of Zeus, whose infidelity has given the women occasion to retort. What we should naturally expect them to say would be to this effect: 'For now one of the male sex is proving himself ungrateful.' Now this is the point at which it will serve us to know the peculiar import of the form $\dot{a} \mu \nu \eta \mu \sigma \sigma \dot{v} v \eta$. It is a sign namely that Euripides intends to pay the rhapsodists in their own coin. Holding fast to this clue and retracing the faulty sentence, we may perhaps see a new possibility of significance in $\Delta$ ios

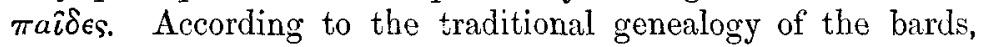
as we see it in the Theogonia of 'Hesiod,' the female sex were not children of Zeus at all. While men, in the tables of these partial antiquaries, were allowed to trace their pedigree through this or that god up to the father of gods and men,

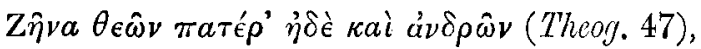

women, that is the sex in general, were thought too wicked and mischievous for so respectable an origin, and were derived, according to the famous legend, from a deceitful temptress fashioned by Hephaestus to humour the wrath of Zeus against mankind (Theog. 570 foll.). Now this Hesiodic fable is immediately followed by the fierce denunciation of the female character to which I have already referred, and though that particular passage cannot have been intended by Euripides (for as Professor Paley observes in his note there it makes no mention of infidelity), it may be taken for a characteristic specimen, and the habitual attacks to which Euripides does 
refer were probably conceived in the same vein and introduced in the same way. (It will be observed that we are in no way concerned with the genuineness of the passage cited as professing to date from the age of the historic Hesiod.) We shall restore therefore to Euripides both the required sense and an appropriate allusion if (reserving the consideration of $\delta$ ), for

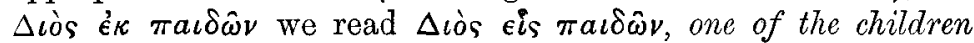
of Zeus. For the palaeographical ground of this correction I must refer the reader to Cobet, Var. Lect., pp. 14, 124, \&c., where he will find ample illustration of the confusion between $\iota \sigma(\mathrm{IC})$ and $\kappa(\mathrm{K})$. The difference between the two is a matter of hair-breadths. Of course the slight emphasis on $\epsilon i s$ and the fact that Xuthus actually traced from Zeus only improves the point. It remains to deal with $\delta$, which is now more impossible than ever. Here, however, speculation is confined to the narrowest limits, for the Greek language scarcely offers a dozen words which satisfy the conditions. We require to complete the metre a short monosyllable beginning with a consonant. The problem thus presented might well appear insoluble if we were bound by the use of common Attic. It does not offer the slightest difficulty if we have been led to expect traces of Epic idiom. In the ballad poetry the force of the Latin etenim, or Attic rє yá $\rho$ (Shilleto, Fals. Leg. \$ 176), might be given by the conjunctions in the order $\gamma^{\prime} \alpha \tau \epsilon$ (see Lexicon s. vv., ra'p and $\tau \epsilon$ ). The use of this idiom here would bo exactly in keeping with the context-

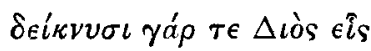

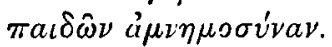

To an editor ignorant of the principle of Euripides' Ionisms this $\tau \epsilon$ would seem simply absurd, and the necessity of getting rid of it would facilitate the perversion of $E I C$ into $E$ K. To offer this as certain would be impertinent, but it is a new thread in an old maze, and may at least lead others to something better. That $\epsilon \hat{i s}$ is the right word I am strongly disposed to believe. In 1098, as the sense is exactly right and the corresponding 1082 is completely above suspicion, I should accept the substitution of $\pi \epsilon \rho i$ for the equivalent $a \mu \phi i$ (Paley), though I cannot satisfy myself as to the cause of the corruption. 
To one of the sources of dactylic poetry which have thus been indicated-the Epic, the Elegiac, and the Gnomic-may be assigned at the first inspection most of the examples which we have to consider. Euripides has in the Andromache a short passage in elegiac couplets, and in the Troades one still shorter.in the hexameter. Both exhibit among the characteristics

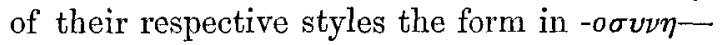

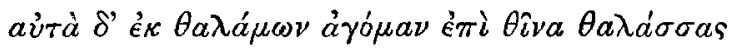

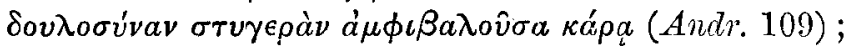

and again-

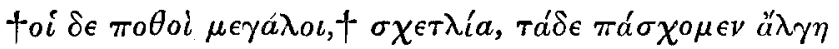

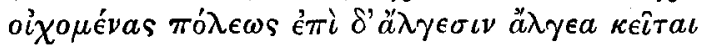

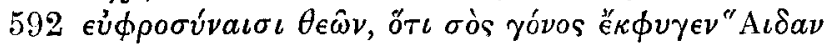

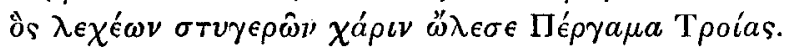

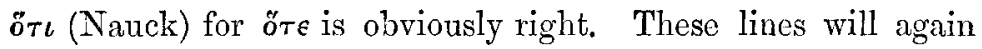
exemplify the necessity of tracing the associations which had formed about words employed by the tragedians if we would understand the tragedians themselves. In 592 the reading of the Aldine edition is $\epsilon \dot{v} \phi \rho \circ \sigma v v a \iota \sigma \iota$, which was for some time accepted. Victorius in his marginal notes gives $\delta v \sigma \varepsilon v \phi \rho o \sigma \dot{v}-$ vaı $\iota$ (Matthiae, ad loc.), which being impossible may be safely accepted as a genuine extract from his MSS. The prevalent reading of our MSS. is $\delta v \sigma \phi \rho o \sigma \dot{v} a \iota \sigma \iota$; Nauck (Studien, p. 143) speaks of 'geringfügige Einzelheiten,' among which may be

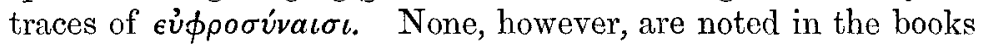
before me. That the Aldine editors did not deliberately invent

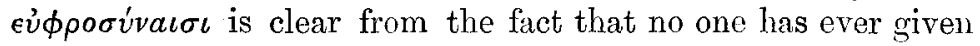
a tolerable interpretation of it, the old eum deorum lactitia being out of the question, whereas $\delta v \sigma \phi \rho o \sigma v i v a \sigma l$, which has a semblance of meaning, may very well have sprung from a correction. It has, however, a semblance of meaning and

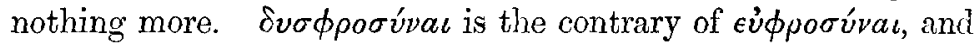
signifies evil cheer, melancholy, as opposed to good cheer, festivity (see Lexicon). I find no evidence whatever that either word could have any other signification. The use of the Doric form $\delta v \sigma \phi \rho o ́ v a$ confirms it, and even $\delta \dot{\sigma} \sigma \rho \omega \nu$ has in Euripides no other sense than $s a d$, the statement to the contrary in the 
Lexicon notwithstanding. And if $\delta \dot{v} \sigma \phi \rho \omega \nu$ hostile were frequent in Tragedy instead of depending upon a single passage (Aesch. Agam. 834 is ambiguous), we might still demur to $\delta v \sigma \phi \rho o \sigma u ́ v a \iota$, hostility: $\epsilon u ̈ \phi \rho \omega \nu$, friendly, is moderately fre-

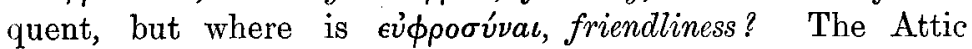
writers did not form these words: they took them from the dactylic poets with their senses already determined. The proper translation of $\delta v \sigma \phi \rho o \sigma v ́ v a \iota \sigma \iota \theta \epsilon \hat{\omega} \nu$ is not by the hostility but by the sadness of the gods,. which being fixed, we shall

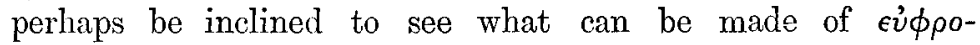
ov́vaı a cheerful state of mind to denote the material comforts producing it, just as we speak in English of 'a festivity,' or 'the yood cheer upon the table.' Indeed from Homer to the tragedians it has scarcely any other sense, in the tragedians no other, than that of 'festival.' Is there any reason why it should not have that sense here? These lines are addressedin a tone of reproach $\left(\sigma \chi \in \tau \lambda i^{\prime} a\right)$ - by the captive Andromache to the captive Hecuba. They refer in an allusive way to the familiar story of Paris, his escape when exposed as a child, his judgment, and its consequences. Now the preservation of the infant Paris was connected with his 'detested bridal' by an important link, the fall of the apple in the 'fair Peleian banquethall,' and it was therefore, as Andromache says, along of the yods' festival (causal dative) that he became the destroyer of Troy. The marriage of Peleus and Thetis is not described in the rhapsodies which time has left to us, but it was part of the best known cycle, and a Greek audience must have heard a hundred times descriptions of the $\theta \epsilon \hat{\omega} \nu$ e $\dot{v} \phi \rho o \sigma v$ va occasion, such as Catuljus gives us in a Latin dress.

Not liking to quote what I cannot construe, I am obliged to add a remark upon 590. Considering that these lines have been much talked over, it is odd if no one has fallen foul of

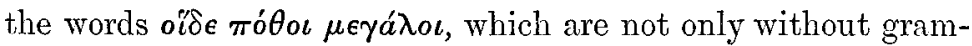
matical construction but contain the very questionable plural

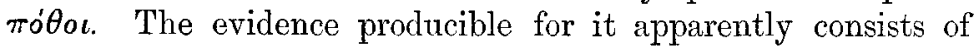
(1) Ocd. Col. 333-

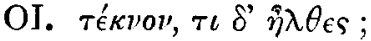

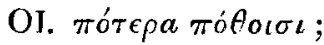

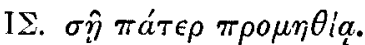

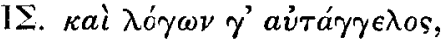


itself on various grounds doubtful- $\pi_{0} \theta 0 \hat{v} \sigma a$ has been suggested. (2) Iph. A. 556-

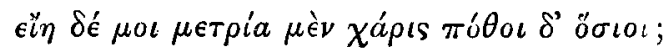

of which it is enough to say that if it came from a less dubious text it would be little more to the point than the citation in the

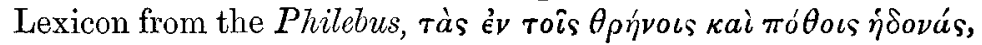
where the plural gives what is vaguely but intelligibly called a 'general' sense, 'cases of mó $\theta$ os.' Considering how very common the word is in all sorts of literature, this is a slender base on which to rest oi $\delta \in \pi o$ to $\theta$ c. Moreover this nominative is, as was said, unconstruable. The source of mischief is, I conceive, to be sought in $\mu \epsilon \gamma a ́ \lambda o$, which has absorbed an indepen-

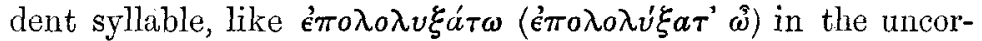
rected MS. of Aesch. Cho. 942. ME $\mathbf{A N} \Omega$ has been misread

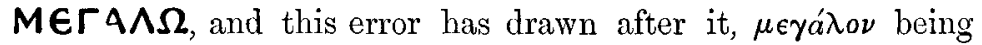

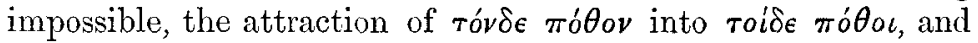
the separation of the first three words from the context, for in the Vatican MS. (see Dindorf's App. crit.) they are assigned to the chorus, absurdly no doubt but by no means without excuse. The step to the ordinary oi $\delta \epsilon$ would be a matter of course. I would read then-

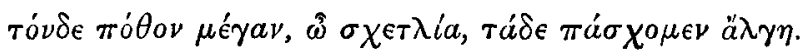

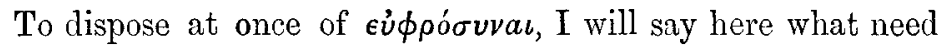
be said about Eur. Bacchae, 375-

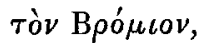

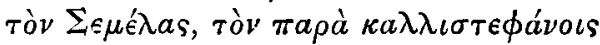

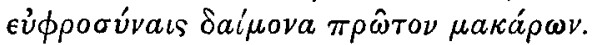

Here the epithet $\kappa a \lambda \lambda \iota \sigma \tau \epsilon \phi a ́ \nu o r s$ gives the sense of $\epsilon \dot{u} \phi \rho \circ \sigma \dot{v}-$ vals-banquet-at a glance. The repetition of the article, by a well-known use, marks the appellations before which it stands as quoted not bestowed by the speaker (Soph. Ai. 726, Eur. Hipp. 587, Med. 206, \&c). I need not, however, go about to prove what no one could ever doubt, that these lines are intended to recall the titles by which Dionysus was invoked in the songs and hymns which were the chief ornament of 'crowned festivities.' Nothing therefore could be more natural than the use of the hymnic word. 
Bearing this passage in mind, we will pass to a pair upon which it will throw much light. In each of the plays which Euripides wrote upon the story of the chaste Hippolytus, we naturally hear something of his $\sigma \omega \phi \rho o \sigma v ́ v \eta$ (Hipp. 1365, and Fr. 447), though it is well worthy of attention how little we do hear. In the extant play, the speaker is Hippolytus himself, carried dying on to the stage and inviting compassion for lis undeserved destruction-

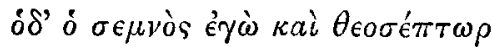

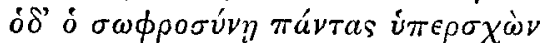

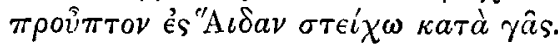

Looked at from the dramatic point of view, these phrases introduced with the repeated article $\left(\dot{o} \ldots \delta^{o}\right)$ mark merely the established character, and in the mouth of Hippolytus as a dramatis persona have of course no literary reference. But it by no means follows that no such reference was to be made by the audience; and we observe the presence not only of $\sigma \omega \phi \rho o \sigma \dot{\nu} \eta \eta$ but of $\theta \epsilon \sigma \sigma \epsilon^{\prime} \pi \tau \omega \rho$, a form, as I must here assume but may elsewhere show, assignable to the same peculiar sources. But by what channel either $\sigma \omega \phi \rho o \sigma v ́ v \eta$ or $\theta \epsilon o \sigma \epsilon ́ \pi \tau \omega \rho$ descended we might scarcely have discovered, had we not been put upon the track by the allusion to the titles of Dionysus in the Bacchae. We know that the virtues of the canonized Hippolytus -if I may venture to use a term which really conveys the force of the Greek $\ddot{p} \rho \omega s$ much better than the completely different word which modern languages have made out of it-were celebrated at Troezen by a regular festival with its accompaniment of hymns, according to the promise of Artemis (Hipp. 1423)-

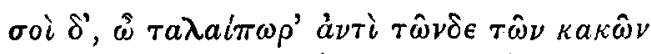

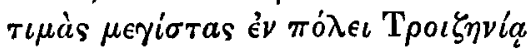
$\delta \omega ́ \sigma \omega . . . .$.

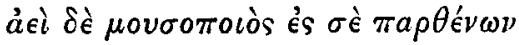

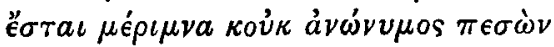

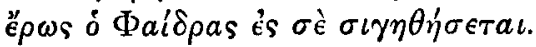

In fact it is more than likely that these hymms furnished Euripides with the plot of his play. Under these circumstances it H. S.-VOL. I. 
would not be a very great stretch of hypothesis to suppose without further evidence that the appeal of the dying martyr gained effect by justifying in advance the ascriptions of his worshippers, and that if we had the Hippolytean hymns we should find many preludes in such a form as this-

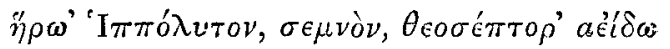

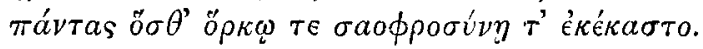

But conjecture becomes affirmation when we find that in the fragment of the lost Hippolytus, which, we may reasonably suppose, praised his $\sigma \omega \phi \rho o \sigma u v \eta$ as much and named it as little as the play which is left to us, the testimony cited for tho virtue is that of these very rites by which it was renowned and rewarded (Eur. $F r \cdot 447$ ) -

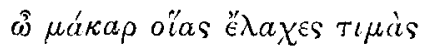

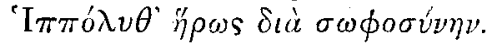

With these examples to guide us, we shall not be inclinol to attribute to accident the curious difference of phraseology between the preface and the prayer which compose the speech of Antigone in Eur. Phoen. 185, foll. The lines are not quite clear to me in metre, but the general drift and the contrast which I am about to point out can be sufficiently ascertained-

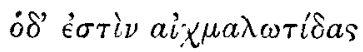

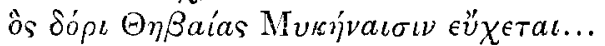

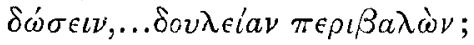

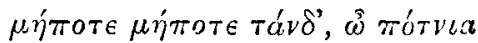

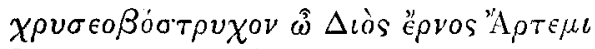

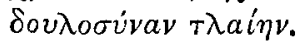

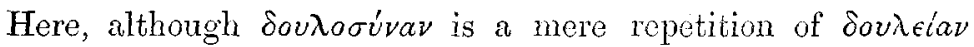
$\left(\tau \alpha^{\prime} \nu \delta \epsilon\right)$, the word is changed in order that the religious formula of the petition may be duly concluded in religious language. To the same influence we can assign the two remaining instances in Aeschylus (Theb. 111, 240), though we should hardly have detected it without the previous comparison of moic strongly-marked examples- 


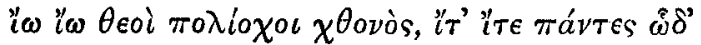

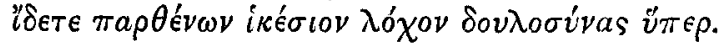

And again,

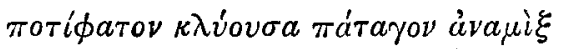

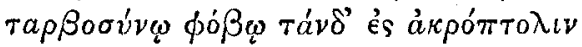

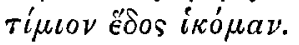

The chorus of the Seven against Thebes exercises, especially in the earlier part of the play, a function essentially religious. The greater part of their first song is a solemn supplication for help addressed to the protecting gods of the city, each of whom

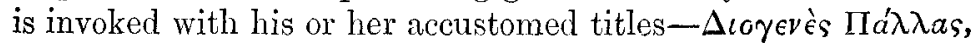

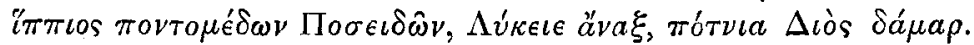
The commencement of the hymn proper is marked, as will be seen by a glance at the context, by the first citation, which is similar to that from the Phoenissae and considering the common subject of the two plays can hardly have been absent from Euripides' mind; so that here we have a commentary upon Aeschylus of the first order, and may listen to the older poet with the ear of the younger. The piety of these Theban women has a dramatic even more than an ethical purpose. Their terror is not in sharper contrast with the courage of Eteokles, than their dependent faith ( $\theta$ cois miovvos, 212) with his self-reliant and contemptuous pride. In the development of this contrast (182-241) the poet has employed his utmost art. The rebukes of the prince are in the smooth iambic, while the chorus reply in the passionate rhythm of their hymn. Calmed, or rather quelled by his authority, they subside at length into dialogue, and the close of the first mood is marked by the second citation-

Look, O our lords, upon us and upon our supplication:

And deliver us not into captivity...

On a sudden I heard a mingled noise, and I was horribly afraid:

So I came up into the sanctuary, even unto the holy hill.

By the prayer of Antigone and the prayer of the women of Thebes we may set-and the comparison will be comment enough-the thanksgiving of the old counsellors of Kreon in the 
292 ON SOME IONIC RLEMENTS IN ATIIC TRAGEDY.

Antigone of Sophokles (148) for the rolling away of the same danger-

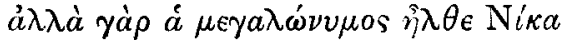
$\tau \hat{a} \pi о \lambda v a \rho \mu a ́ t \omega \dot{a} \nu \tau \iota \chi \alpha \rho \in \hat{\imath} \sigma a \Theta \dot{\eta} \beta a$,

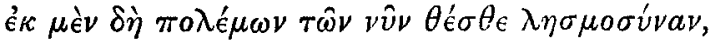

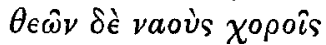

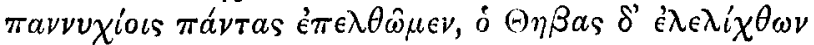

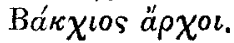

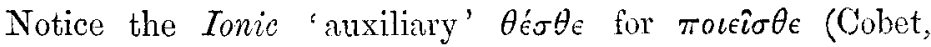
Nov. Lec. 261).

A. W. VerralL.

(To the continned.) 